\title{
Interpretation of fine needle aspiration cytology of thyroid: do we need a better classification?
}

\author{
Bimalka Seneviratne ${ }^{1}$ \\ Sri Lanka Journal of Diabetes, Endocrinology and Metabolism 2012; 2: 32-34
}

Fine needle aspiration cytology technique (FNAC) is a very popular first line investigation for disorders of the thyroid gland. It is a rapid and cost effective technique that can be easily performed in any category of patients. This technique provides useful information for the clinician to plan out the strategy for management of patients.

It is critical therefore that the cytopathologist communicate thyroid FNA interpretations to the referring physician in terms that are unambiguous and clinically useful.

The currently used classification for thyroid FNAC includes the following categories.

Thy 01 - Inadequate

Thy 02 - Benign (colloid goiter, thyroiditis, toxic goiter)

Thy 03 - Follicular proliferation (follicular neoplasm, hurthle cell neoplasm, adenomatoid nodule)

Thy 04 - Suspicious for malignancy

Thy 05 - Malignant (papillary, medullary, anaplastic carcinoma)

Lesions are classified as "Thy 01" when the cellular yield is inadequate. This is often encountered following the aspiration of highly vascular nodules and cystic lesions. One of the main advantages of this cost effective technique is that it can be easily repeated within a short time.

When there is unequivocal evidence of a benign condition such as colloid goiter, thyroiditis and hyperplastic nodule the lesion will be classified as "Thy 02 ”.

“Thy 03/follicular proliferation” category of the above classification includes a significant number of pathological entities with different clinical outcomes. Conditions that qualify to be included within the "Thy 03” category are hyperplastic nodules with highly cellular smears, florid thyroiditis, neoplastic lesions such as follicular adenoma/carcinoma, hurthle cell tumours (hurthle cell adenoma/carcinoma) and certain types of papillary carcinoma, such as follicular variant of papillary carcinoma when the cytological findings are equivocal. Hence the spectrum of diseases within the "Thy 03" group is comparatively wide.

As such, from clinician's point of view a cytological diagnosis of "Thy 03" in the current classification provides little information to plan out the management. Some of the pathological conditions within "Thy 03" do not require surgery and can be managed effectively by medical intervention. Conditions that require surgery need a further qualification as to the precise nature of the lesion. A significant number of "Thy 03" lesions end up with lobectomies as this category does not separate neoplastic from non-neoplastic lesions and benign from malignant conditions. Hence a cytological diagnosis of “Thy 03/follicular proliferation” fails to provide clinically useful information in most of the cases with regard to the management of the patient.

Thyroid lesions that have some but not all the features of malignancy are included in "Thy 04” category. The “Thy 05” category includes lesions having unequivocal cytological features of malignancy.

Time has arrived to change to a better classification that provides useful information to the clinician enabling him to decide the treatment option. By this means the number of unnecessary thyroid surgery for patients with thyroid disorders can be effectively reduced.

The Bethesda system for reporting thyroid cytology (BSRTC) consists of six diagnostic categories. It provides the definitions and morphologic criteria for the different categories. For clarity of communication, the Bethesda system for reporting thyroid cytopathology recommends that each thyroid FNA report begin with one of the diagnostic categories.

The BSRTC diagnostic categories are shown in Table 1. 
Table 1. The BSRTC diagnostic categories

I. Non diagnostic or unsatisfactory

II. Benign

III. Atypia of undetermined significance or follicular lesion of undetermined significance

IV. Follicular neoplasm or suspicious for a follicular neoplasm

V. Suspicious for malignancy

VI. Malignant

The Bethesda system provides definitions and morphologic criteria for the different categories. For the general categories, some degree of sub categorization which is appropriate has been allowed. Recommended terminology for sub categorization is shown in Table 2.

Table 2. Recommended terminology for sub categorization in the BSRTC

I. Non diagnostic or unsatisfactory

Cyst fluid only, acellular, obscuring blood

II. Benign

Colloid goiter, adenomatoid nodule, Hashimoto's thyroiditis, granulomatous thyroiditis

III. Atypia of undetermined significance or follicular lesion of undetermined significance

IV. Follicular neoplasm or suspicious for a follicular neoplasm

Specify if hurthle cell (oncocytic) type

V. Suspicious for malignancy

Suspicious for papillary carcinoma

Suspicious for medullary carcinoma

Suspicious for metastatic carcinoma

Suspicious for lymphoma

Other

VI. Malignant

Papillary carcinoma

Medullary carcinoma

Poorly differentiated carcinoma

Anaplastic carcinoma

Metastatic carcinoma

Lymphoma

Other

Each diagnostic category has an implied risk of malignancy. In addition to that useful information, in the Bethesda system of classification of thyroid cytopathology each category has been linked to evidence based clinical management guidelines as shown in Table 3. 
Table 3. Risk of malignancy in the BSRTC categories

\begin{tabular}{lcl}
\hline Diagnostic category & Risk of malignancy (\%) & Management \\
\hline Non- diagnostic or unsatisfactory & - & Repeat FNA with ultrasound guidance \\
Benign & $0-3$ & Clinical follow up \\
$\begin{array}{l}\text { Atypia of undetermined significance } \\
\text { or follicular lesion of undetermined } \\
\text { significance }\end{array}$ & $5-15$ & Repeat FNAC \\
$\begin{array}{l}\text { Follicular neoplasm or suspicious } \\
\text { for a follicular neoplasm }\end{array}$ & $15-30$ & Surgical lobectomy \\
Suspicious for malignancy & $60-75$ & Near total thyroidectomy or surgical lobectomy \\
Malignancy & $97-99$ & Near total thyroidectomy \\
\hline
\end{tabular}

The Bethesda system for reporting of thyroid cytology provides clinically useful information as each diagnostic category is linked to a management option.

Time has arrived for a change in the reporting of thyroid cytopathology. Advantages of the proposed Bethesda system for reporting thyroid cytology has to be understood. It is of paramount importance for the clinicians to be aware of the diagnostic categories and the appropriate management options of the BSRTC. Consensus opinion with regard to the application of BSRTC can be arrived by clinicopathological discussions and collaborative meetings involving the specialists of clinical and paraclinical fields.

\section{References}

1. Baloch ZW, Li Volsi VA, Asa SL, et al. Diagnostic terminology and morphologic criteria for cytologic diagnosis of thyroid lesions: a synopsis of the National Cancer Institute Thyroid Fine-Needle Aspiration State of the Science Conference. Diagn Cytopathol 2008; 36(6):425 37.

2. Jing X, Michael CW, Pu RT. The clinical and diagnostic impact of using standard criteria of adequacy assessment and diagnostic terminology on thyroid nodule fine needle aspiration. Diagn Cytopathol 2008; 36(3): 161-6.
3. Layfield LJ, Abrams J, Cochand-Priollet B, et al. Postthyroid FNA testing and treatment options; a synopsis of the National Cancer Institute Thyroid Fine Needle Aspiration State of the Science Conference. Diagn Cytopathol 2008; 36(6): $442-8$.

4. Baloch ZW, Cibas ES, Clark DP, et al. The National Cancer Institute Thyroid Fine Needle Aspiration State of the Science Conference: a summation. Cytojournal 2008; 5: 6.

5. Weber D, Brainard J, Chen L. Atypical epithelial cells, cannot exclude papillary carcinoma, in fine needle aspiration of the thyroid. Acta Cytol 2008; 52(3): 320 - 4.

6. Kini SR. Thyroid Cytopathology: An Atlas and Text. Philadelphia: Lippincott Williams \& Wilkins; 2008.

7. Yassa L, Cibas ES, Benson CB, et al. Long term assessment of a multidisciplinary approach to thyroid nodule diagnostic evaluation. Cancer 2007; 111(6): 508-16.

8. Cooper DS, Doherty GM, Haugen BR, et al. Management guidelines for patients with thyroid nodules and differentiated thyroid cancer. Thyroid 2006; 16(2): 109-42.

9. Wang HH. Reporting thyroid fine-needle aspiration; literature review and a proposal. Diagn Cytopathol 2006; 34(1):67 - 76.

10. Faquin WC, Cibas ES, Renshaw AA. Atypical cells in fineneedle aspiration biopsy specimens of benign thyroid cysts. Cancer 2005; 105(2): 71 - 9 . 